\title{
LETRAMENTO MIDIÁTICO DE PROFESSORES E O ENSINO REMOTO EMERGENCIAL NA PANDEMIA DE COVID-191
}

\author{
TEACHERS'S MEDIA LITERACY \\ AND EMERGENCY REMOTE TEACHING IN THE COVID-19 PANDEMIC
}

\author{
ALFABETIZACIÓN MEDIÁTICA DE PROFESORES \\ Y ENSEÑANZA REMOTA DE EMERGENCIA EN LA PANDEMIA COVID-19
}

Joana Sobral Milliet² ; Rosalia Duarte ${ }^{3}$ José Mauricio Avilla Carvalho ${ }^{4}$

\begin{abstract}
RESUMO
Neste texto apresentamos resultados de uma pesquisa realizada em 2020 que, utilizando questionário on-line, buscou identificar a percepção de professores do ensino fundamental e médio que estavam realizando ensino remoto emergencial sobre suas habilidades de letramento midiático. Os dados obtidos no questionário foram submetidos a análises descritivas e ao teste qui-quadrado, com o objetivo de identificar possíveis associações entre diferentes variáveis. Entre os principais resultados, destacamos a elevada percepção de habilidades de letramento midiático por parte de professores, assim como o uso dessas habilidades na educação remota emergencial. Os testes indicaram associação entre o costume de propor práticas de letramento midiático na escola antes da pandemia e uma maior percepção e uso dessas habilidades por parte dos professores na educação remota. Foi identificada, também, entre os professores de escolas estaduais, uma baixa percepção de competência para a compreensão do uso que as big techs fazem de seus dados, indicando que podem estar vulneráveis aos grandes grupos privados que gerenciam essas plataformas e também pouco preparados para orientar seus alunos sobre o tema. Reafirmamos a necessidade de uma abordagem crítica para o letramento midiático, com foco não só no conhecimento sobre o uso dos dados dos usuários, mas também no funcionamento dos algoritmos, indispensável para compreender como opera o chamado capitalismo digital e para o exercício das práticas sociais de uso das mídias, especialmente neste momento, em que nos tornamos dependentes das tecnologias para estudo, trabalho e relações sociais, devido ao distanciamento físico imposto pela pandemia de Covid-19.
\end{abstract}

PALAVRAS-CHAVE: Letramento midiático. Ensino remoto emergencial. Capitalismo digital.

\footnotetext{
${ }^{1} \mathrm{O}$ presente trabalho é fruto de tese de doutorado em andamento e foi realizado com apoio do Conselho Nacional de Desenvolvimento Científico e Tecnológico (CNPq) e da Coordenação de Aperfeiçoamento de Pessoal de Nível Superior - Brasil (CAPES) - Código de Financiamento 001.

${ }^{2}$ Doutoranda em Educação - Pontifícia Universidade Católica do Rio de Janeiro (PUC-Rio). Rio de Janeiro, RJ Brasil. Mestre em Educação - Universidade Federal do Estado do Rio de Janeiro (UNIRIO). Rio de Janeiro, RJ Brasil. E-mail: joanamilliet@gmail.com

${ }^{3}$ Doutorado em Educação - Pontifícia Universidade Católica do Rio de Janeiro. Rio de Janeiro, RJ - Brasil. Professora associada - Pontifícia Universidade Católica do Rio de Janeiro. Rio de Janeiro, RJ - Brasil. E-mail: rosalia@puc-rio.br

${ }^{4}$ Doutorando em Educação - Pontifícia Universidade Católica do Rio de Janeiro. Rio de Janeiro, RJ - Brasil.

E-mail: josemauricioavilla@gmail.com
}

Submetido em: 02/06/2021 - Aceito em: 04/11/2021

(C) ETD- Educação Temática Digital v. 24

n.1

p. $32-52$

jan./abr. 2022 


\section{ABSTRACT}

In this text, we present the results of a research conducted in 2020 that, using an online survey, sought to identify the perception of elementary and high school teachers, who were performing emergency remote teaching, about their media literacy skills. The data obtained in the questionnaire were subjected to descriptive analyzes and to chi-square test, in order to identify possible associations between different variables. Among the main results, we highlight the high perception of media literacy skills by teachers, as well as the use of these skills in emergency remote education. The tests indicated an association between the custom of proposing media literacy practices at school before the pandemic and a greater perception and use of these skills by teachers in remote education. It was also identified, among state school teachers, a low perception of competence to understand the use that big techs make of their data, indicating that they may be vulnerable to large private groups that manage these platforms and also poorly prepared to guide your students on the topic. We reaffirm the need for a critical approach to media literacy, focusing not only on knowledge about the use of user data, but also on the functioning of algorithms, which is essential for understanding how the so-called digital capitalism operates, and for the exercise of social practices of use of media, especially at a time when we've become dependent on technologies for study, work and social relationships due to the physical distance imposed by the Covid-19 pandemic.

KEYWORDS: Media literacy. Emergency remote teaching. Digital capitalism.

\section{RESUMEN}

En este texto, presentamos los resultados de una investigación realizada en 2020 que, mediante un cuestionario en línea, buscó identificar la percepción de los docentes de primaria y secundaria que estaban realizando enseñanza remota de emergencia sobre sus habilidades de alfabetización mediática. Los datos obtenidos en el cuestionario fueron sometidos a análisis descriptivos y al test chi-cuadrado, con el objetivo de identificar posibles asociaciones entre diferentes variables. Entre los principales resultados, destacamos la alta percepción de las habilidades de alfabetización mediática por parte de los docentes, así como el uso de estas habilidades en la educación remota de emergencia. Las pruebas indicaron una asociación entre la costumbre de proponer prácticas de alfabetización mediática en la escuela antes de la pandemia y una mayor percepción y uso de estas habilidades por parte de los docentes en educación remota. También se identificó una baja percepción de competencia para comprender el uso que las big techs hacen de sus datos entre los docentes de las escuelas públicas, lo que indica que pueden ser vulnerables a los grandes grupos privados que manejan estas plataformas y además poco preparados para orientar a sus alumnos en el tema. Reafirmamos la necesidad de un enfoque crítico de la alfabetización mediática, centrándose no solo en el conocimiento sobre el uso de los datos de los usuarios, sino también en el funcionamiento de los algoritmos, que es fundamental para comprender cómo opera el llamado capitalismo digital y para el ejercicio de prácticas sociales de uso de los medios de comunicación, especialmente en un momento en el que nos volvemos dependientes de las tecnologías para el estudio, el trabajo y las relaciones sociales debido a la distancia física que impone la pandemia Covid-19.

PALAVRAS-CLAVE: Alfabetización mediática. Enseñanza remota de emergencia. Capitalismo digital.

\section{INTRODUÇÃO}

Em março de 2020, a Organização Mundial da Saúde (OMS) declarou a pandemia mundial do novo coronavírus (Covid-19). No Brasil, repentinamente, escolas, escritórios e comércios foram fechados na tentativa de diminuir as taxas de disseminação da Covid-19, uma doença com alta letalidade. Grande parte da população passou a trabalhar em casa, em home office, e a escola precisou migrar do modelo presencial para o remoto

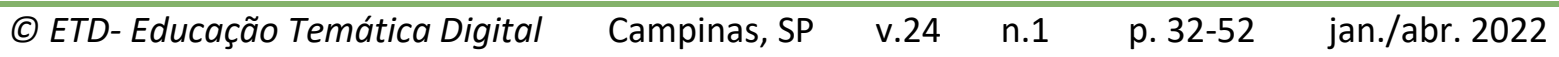


mudam rapidamente, modificam as mídias e são por ela modificados (BUZATO, 2010; PEREIRA; PINTO; MOURA, 2015). Assim, o domínio de diferentes tipos de linguagem e formas de comunicação produz diferentes letramentos. De acordo com Soares (2002), os indivíduos letrados possuem competências discursivas e cognitivas para exercerem efetivamente práticas sociais de interação com os outros e com o mundo. Nesse sentido, o letramento midiático não se restringe a habilidades mecânicas ou ao uso instrumental das mídias, mas constitui-se como condição para a reflexibilidade e requisito para o exercício da cidadania.

Pereira, Pinto e Moura (2015) argumentam que formas de acesso e de recepção, uso crítico, produção e participação cívica configuram as muitas definições de letramento midiático. Para Scolari (2018), algumas concepções do termo são relacionadas à proteção de crianças e jovens face a influências negativas, enquanto outras se referem ao desenvolvimento da consciência crítica; "[...] alguns lidam com a gramática básica do meio, enquanto outros têm uma abordagem mais conceitual e abrangente." ${ }^{6}$ (SCOLARI, 2018, p. 5, tradução nossa).

Apesar da expressão "letramento midiático" ter sido bastante incorporada ao discurso político de governos de muitos países, a partir da década de 2000 , especialmente na Europa e na América do Norte, Buckingham $(2019,2020)$ alerta que a expressão figura nos documentos governamentais mais como retórica relacionada a uma necessidade da vida moderna, do que como um compromisso intrínseco à política educacional. Para ele, a efetividade da proposta implica sua vinculação à prática educativa, a partir da implementação de programas fundamentados e contínuos de mídia-educação.

Face às diferentes definições de letramento midiático, o estudo aqui relatado toma como parâmetro teórico-metodológico as definições do termo, formuladas por David Buckingham (2019, 2020), Sara Pereira (2000), Sonia Livingstone (2011), Eshet-Alkalai (2012) e Henry Jenkins (2009). De forma geral, os conceitos de letramentos midiáticos adotados por esses autores convergem para a aquisição de competências e habilidades de análise e uso de mídias, de ordens diversas, em diferentes contextos.

Esses pesquisadores elencam em seus modelos teóricos de letramento midiático um conjunto de habilidades consideradas fundamentais para usufruir das oportunidades que as mídias oferecem, em especial as habilidades que se referem à aquisição de novos conhecimentos, incluindo a proteção contra riscos ou danos ao bem-estar físico e mental, à segurança pessoal, à privacidade, entre outros. São elas: realizar análises e interpretações

6 "[...] algunas tratan sobre la gramática básica del medio, mientras que otras tienen un enfoque más conceptual y de mayor alcance."

$\begin{array}{llllll}\text { (C) ETD-Educação Temática Digital } & \text { Campinas, SP } & \text { v.24 } & \text { n.1 } & \text { p. 32-52 } & \text { jan./abr. } 2022\end{array}$


críticas do conteúdo das mídias; entender e explicar as linguagens utilizadas pelas mídias e a forma como elas são produzidas; analisar/entender fotografias e imagens gráficas em geral; perceber as intenções do produtor do conteúdo veiculado nas mídias, seja ele um usuário individual ou uma grande empresa de comunicação; identificar o tipo de público para quem é direcionado um conteúdo ou mensagem (jovens, crianças, mulheres, estudantes universitários etc.); compreender como e para que as mídias digitais usam os dados dos seus usuários enquanto navegam na internet; produzir e compartilhar conteúdos (textos, vídeos, áudios) em diferentes mídias.

De um modo geral, as pesquisas dispõem de instrumentos específicos com medidas padronizadas para avaliar o letramento midiático de professores, como o DigCompEdu (LUCAS; MOREIRA, 2018). Nesse contexto de investigação, relacionado à implementação do ensino remoto emergencial, optamos por não adotar medidas padronizadas e buscamos, primordialmente, identificar a percepção que os professores que estavam realizando esse tipo de ensino tinham de suas facilidades e de suas dificuldades com mídias, ou seja, a percepção deles sobre seu próprio letramento midiático.

\section{METODOLOGIA}

O questionário on-line foi direcionado a professores da educação básica e teve como objetivo identificar a percepção deles em relação ao próprio letramento midiático, convidando-os a conceder entrevistas sobre suas práticas educativas no ensino remoto. 0 questionário circulou por dois meses, ao final dos quais não houve novos respondentes. Responderam ao questionário 264 sujeitos, sendo 259 efetivamente professores da educação básica e os demais estavam em cargos de gestão naquele momento. $\mathrm{Na}$ composição das análises, foram consideradas somente as respostas dos professores que estavam em atividade de docência.

O questionário foi estruturado em três quesitos, compostos por um total de 22 itens. Na apresentação, era explicada a proposta de pesquisa e solicitava-se a adesão ao termo de consentimento livre e esclarecido, assegurando o comprometimento ético com os dados obtidos e garantindo o anonimato dos respondentes - conforme os procedimentos recomendados pela Comissão Nacional de Ética em Pesquisa - CONEP (BRASIL, 2021). O primeiro quesito do instrumento envolvia questões relativas ao perfil sociodemográfico dos professores, como: idade, gênero, segmento e local de trabalho (escola pública ou privada), nível socioeconômico, formação acadêmica e tipo de conexão à internet. O segundo quesito era composto por itens relacionados às práticas de educação remota que os professores estavam vivenciando, com questões sobre: os tipos de recursos remotos utilizados pela escola; formatos das atividades pedagógicas; modos de interação com os alunos, apoio recebido pelos professores, aprendizados, entre outros. O terceiro e último quesito se

$\begin{array}{llllll}\text { (c) ETD-Educação Temática Digital } & \text { Campinas, SP } & \text { v.24 } & \text { n.1 } & \text { p. 32-52 } & \text { jan./abr. } 2022\end{array}$


referia à percepção dos professores quanto aos letramentos midiáticos, e quanto às habilidades mais utilizadas por eles nas atividades de ensino remoto.

As questões variaram entre modelos fechados, de múltipla escolha, com opção de resposta única e/ou múltipla, modelos em escala e de respostas abertas. Para que o questionário chegasse a um número grande e diversificado de professores, o link de acesso ao formulário foi divulgado em redes sociais, principalmente no WhatsApp, seguindo a técnica de bola de neve - forma de amostra não probabilística, que utiliza cadeias de referência. Essa é uma metodologia adequada para estudar determinados grupos difíceis de serem acessados (HANDCOCK; GILE, 2011), neste caso, por estarem espalhados em uma grande área geográfica (pretendia-se ter acesso a professores de diferentes regiões do país para abranger contextos diversos) e pela crise causada pela pandemia, dificultando a disponibilidade para participação em pesquisa.

As respostas ao questionário foram submetidas a análises por meio do software SPSS-IBM (versão 26). As análises realizadas foram de ordem descritiva e de associação, através do teste qui-quadrado. Trata-se de um teste não paramétrico, isto é, que não depende de parâmetros populacionais, que permite avaliar a associação entre duas variáveis categóricas. Conforme Field (2009, p. 688), o teste consiste na comparação de frequências observadas com as frequências esperadas estatisticamente por categorias. $A$ hipótese nula (Hipótese 0) do teste - aceita com um valor de p maior do que 0,05 - indica uma distribuição aleatória, enquanto a hipótese alternativa (Hipótese 1) - aceita com um valor de $\mathrm{p}$ menor ou igual a 0,05 - denota uma distribuição não aleatória, indicando a existência de uma associação entre as variáveis.

Após a realização dos testes cruzando as variáveis do estudo, reservaram-se para análises post hoc apenas os cruzamentos em que a Hipótese 1 foi aceita ( 0,05$)$, indicando haver associação entre as variáveis comparadas. Além disso, para a seleção dos cruzamentos, atentou-se também para dois critérios relevantes do teste qui-quadrado: (1) as frequências esperadas devem ser maiores do que 5 em pelo menos $20 \%$ dos casos, se possível em todos para garantir um maior poder estatístico da análise; (2) nenhuma frequência esperada deve ser menor do que 1 (FIELD, 2009).

Nas análises post hoc do teste qui-quadrado, verificou-se o valor do $\mathrm{V}$ de Cramer e os valores dos resíduos padronizados e ajustados. O V de Cramer corresponde a uma medida de intensidade da associação existente entre as variáveis categóricas. Já os resíduos representam a diferença entre os valores da frequência observada e da frequência esperada, e a padronização e ajuste têm relação com a transformação desses valores de resíduos para a unidade $Z$ da distribuição normal padronizada (com média $=0$ e desviopadrão = 1). 
Conforme Rea e Parker (2014), considerou-se que: valores do V de Cramer iguais ou maiores que 0 e 0,09 indicam associações insignificantes; valores entre 0,1 e 0,19 indicam associações fracas; entre 0,2 e 0,39 indicam associação moderada; entre 0,4 e 0,59 indicam associação relativamente forte; entre 0,6 e 0,79 há associação forte; e valores iguais ou maiores que 0,8 indicam associação muito forte. Com relação aos resíduos ajustados padronizados, com base em Sharpe (2015), foram considerados como significativos para análise os resíduos ajustados iguais ou maiores do que 1,96. Resíduos ajustados padronizados positivos indicam que a frequência observada é maior do que a esperada, e negativos indicam que a frequência observada é menor do que a esperada.

\section{RESULTADOS E DISCUSSÃO}

Quanto à atuação profissional e perfil sociodemográfico, 76\% dos professores que responderam ao questionário trabalham em escola pública e $23 \%$ em escola particular. A maioria (67\%) tem entre 30 e 49 anos de idade, é do sexo feminino (79\%) e se autodeclarou branco(a) (58\%). A maior parte (64\%) dá aulas para adolescentes entre 12 e 17 anos.

Quanto à formação, $83 \%$ possuem pós-graduação, sendo $29 \%$ com mestrado e $6 \%$ com doutorado. Um percentual elevado se compararmos com dados do Censo Escolar 2019, em que $41,3 \%$ dos professores da educação básica informaram ter pós-graduação (BRASIL, 2020). A alta escolaridade aferida nesta pesquisa provavelmente se deve à amostragem em bola de neve, na qual os "informantes-chave" (HANDCOCK; GILE, 2011), que receberam primeiramente os questionários, eram estudantes de pós-graduação e possivelmente repassaram o questionário a colegas com mesmo nível de escolaridade.

A mesma justificativa aplica-se ao fato de a amostra ter professores com um alto nível socioeconômico, considerando-se os resultados do Censo Escolar 2019, com 42\% tendo informado renda familiar superior a seis salários mínimos. Corrobora o alto nível socioeconômico o fato de $14 \%$ dos professores terem informado que moram sozinhos e $69 \%$ residirem com no máximo três pessoas. Estamos cientes de que a composição socioeconômica da amostra não reflete o conjunto dos professores brasileiros da educação básica que, segundo dados da Pesquisa Nacional por Amostra de Domicílios Contínua (Pnad Contínua), realizada pelo Instituto Brasileiro de Geografia e Estatística - IBGE (CRUZ; MONTEIRO, 2020), têm renda mensal média ${ }^{7}$ na faixa de 3 a 6 salários mínimos. Esse perfil amostral é fruto do contexto social da pandemia, das desigualdades socioeconômicas, tecnológicas e regionais dos professores e de suas desiguais condições de trabalho, o que

\footnotetext{
7 O dado da Pnad refere-se à renda do professor, enquanto nosso questionário pergunta sobre a renda familiar. Ainda assim, a comparação entre os dados demonstra que o perfil dos nossos respondentes foi de nível socioeconômico mais alto do que a média dos professores brasileiros.
}

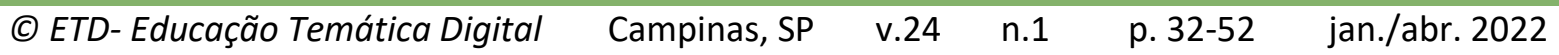


permite a alguns não somente condições de ensinar de forma remota, como também a possibilidade de reservar um tempo em suas atividades cotidianas para participar de uma pesquisa.

Na Tabela 1 consta a distribuição dos entrevistados em relação à dependência administrativa da(s) escola(s) na(s) qual(quais) dão aula.

Tabela 1. Dependência administrativa da(s) escola(s) onde os professores entrevistados trabalham

\begin{tabular}{|ccc}
\hline DEP. ADM. & FREQUÊNCIA & $\%$ \\
\hline PARTICULAR & 71 & $27,41 \%$ \\
FEDERAL & 12 & $4,63 \%$ \\
ESTADUAL & 84 & $32,43 \%$ \\
MUNICIPAL & 137 & $52,9 \%$ \\
\hline
\end{tabular}

Fonte: O(s) autor(es), pesquisa de campo.

Notas: $\mathrm{N}=259$. Os professores podiam indicar mais de uma dependência administrativa onde trabalham.

Os respondentes estão bem distribuídos no território brasileiro. No entanto, a maioria das respostas veio da região Sudeste, sendo $62 \%$ de cidades do estado do Rio de Janeiro e $19 \%$ de cidades do estado de São Paulo, também como consequência da metodologia de bola de neve, pois os primeiros questionários foram disparados para professores do Rio de Janeiro. Os 264 respondentes eram de 66 cidades diferentes, sendo a maioria (45\%) da cidade do Rio de Janeiro, seguida das cidades de São Paulo (9\%) e Fortaleza (5\%).

Um dos primeiros quesitos do questionário dizia respeito à percepção dos professores quanto às ações mais relevantes a serem implementadas pelas escolas junto a estudantes e professores durante a pandemia de Covid-19. A maioria dos participantes (média de 80,5\%) considera que garantir o bem-estar de todos, apoiar o trabalho dos professores e assegurar o vínculo dos alunos com a escola devem ser prioridade para as redes de ensino. Isso indica que esses professores consideravam acolhimento, saúde e afeto como valores prioritários a serem promovidos pelo ensino remoto emergencial. Somente $38,5 \%$ dos professores responderam ser muito importante priorizar as atividades pedagógicas direcionadas à aquisição de conteúdos curriculares; 22,3\% consideram muito importante fazer a avaliação da aprendizagem; e 33,2\% indicaram ser muito importante a revisão da política de escala de notas. Essas respostas demonstram que a manutenção da política educacional de avaliação de resultados não foi considerada uma prioridade pelos

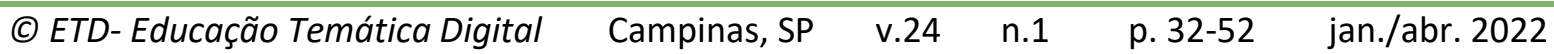


professores naquele momento. Parecem também confirmar a análise do efeito da pandemia na vida social feita, em 2020, por Boaventura de Souza Santos, no ensaio "A cruel pedagogia do vírus", no qual afirma que a crise sanitária reavivou a necessidade de escuta e acolhida, como condição para a preservação das relações sociais, frente à necessidade de dar prosseguimento às atividades regulares da escola.

Quanto à percepção por parte dos professores de suas habilidades de letramento midiático, necessárias à manutenção das atividades escolares durante a pandemia, a maioria dos docentes se percebe significativamente habilidosa, como pode ser constatado no Gráfico 1. Os resultados agregados da análise das variáveis que compõem a percepção das habilidades de letramento midiático indicam que 59\% consideram-se extremamente ou bastante capazes de realizar atividades com mídias. No entanto, perceberam-se menos capazes de "produzir conteúdo para as diferentes mídias" e "entender e explicar as linguagens utilizadas pelas mídias e a forma como elas são produzidas".

Gráfico 1. O quanto você se considera capaz de (porcentagem)

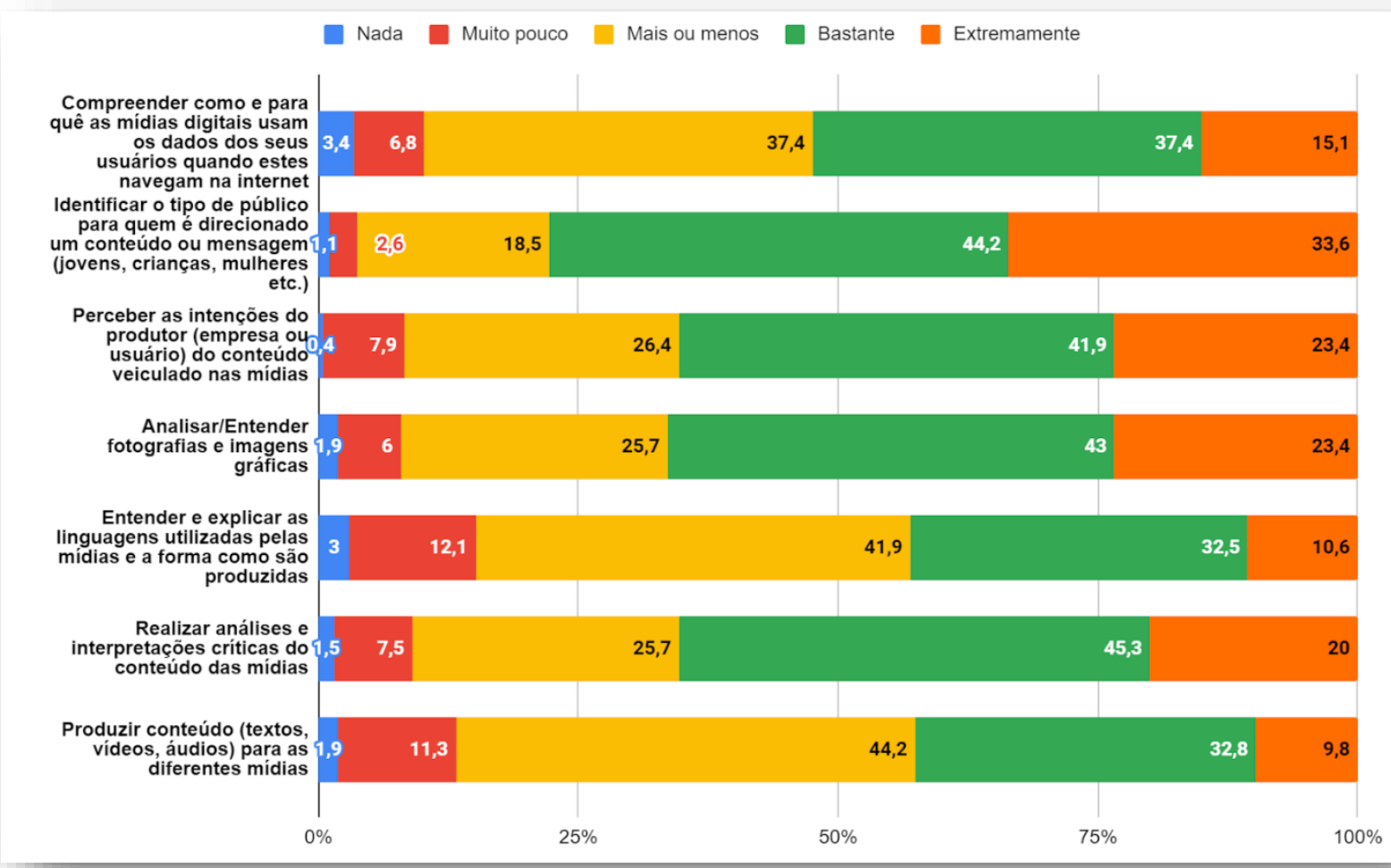

Fonte: Os autores, pesquisa de campo.

Outras pesquisas apresentam resultados similares quanto à elevada percepção de letramento midiático por parte de professores, como o trabalho de Ata e Yildirim (2019) ou

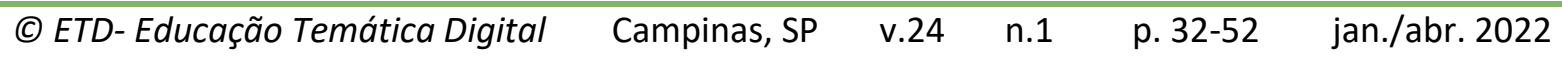


o de Colás-Bravo, Conde-Jiménez e González-Ramírez (2016). Neste último, os autores mostram que a percepção dos professores espanhóis sobre suas competências digitais é bastante elevada. Assim, na pesquisa aqui apresentada, os testes de qui-quadrado realizados mostraram que as variáveis de gênero e o segmento em que lecionam não condicionam as percepções dos professores sobre suas habilidades de letramento midiático e, portanto, não parecem ser fatores que diferenciam a percepção de suas habilidades.

Podemos supor que o fato desses professores terem sido compelidos a fazer uso de mídias digitais para continuar ensinando fora do espaço escolar e da maioria deles ter condições de infraestrutura tecnológica em casa, provavelmente melhores do que tinham na escola (equipamento de qualidade, conexão banda larga com alta velocidade, por exemplo), favoreceram a percepção de que tinham habilidades diversas de letramentos midiáticos. Isso porque $71 \%$ dos professores que participaram da pesquisa possuem conexão com a internet via cabo de TV ou fibra ótica, enquanto $25 \%$ se conectam via modem ou chip (3G ou 4G).

Pesquisas sobre o ensino remoto emergencial, realizadas ao longo de 2020, sintetizadas por Lima (2020), mostram que 39\% das redes de ensino municipais e estaduais afirmavam estar promovendo formações para os profissionais desenvolverem atividades a distância com os estudantes; $57 \%$ dos docentes disseram ter feito cursos de formação sobre aprendizagem em ambientes virtuais e $53 \%$ buscaram tutoriais e dicas na internet. Esses professores, provavelmente, tiveram acesso a numerosos materiais que circularam amplamente na internet (tutoriais, palestras ao vivo, cursos de curta-duração, oficinas, debates etc.) relacionados a como utilizar os recursos digitais e, principalmente, estavam participando direta ou indiretamente do debate público sobre o tema (matérias jornalísticas, textos acadêmicos, eventos governamentais, entre outros). Nunca se discutiu tanto as mídias na educação quanto nesse período. Possivelmente, essas condições favoreceram um sentimento de maior competência em relação ao ensino emergencial remoto com uso das mídias, o que afetou a percepção relacionada às habilidades de letramento midiático.

A formação acadêmica não parece ter impacto na percepção de letramento midiático, já que os testes de qui-quadrado não indicaram relação entre as duas variáveis. Outras pesquisas já haviam apresentado resultados semelhantes, como a de Brasilino (2017), que não identificou correlações significativas entre a formação de professores para o uso de tecnologias da informação e da comunicação (TIC) e a adoção destas em suas práticas pedagógicas, constatando o impacto do aprendizado entre pares no uso pedagógico de mídias no contexto escolar. 
Quando perguntados se antes da interrupção das aulas costumavam propor práticas pedagógicas de letramento midiático para os seus alunos na escola: $63 \%$ dos professores responderam que sim e 34\% disseram que não. Os resultados do teste qui-quadrado e os valores do $\mathrm{V}$ de Cramer para a análise dessas variáveis mostraram associação moderada com correlação positiva entre práticas prévias de professores voltadas para o uso de mídias pelos alunos e seu próprio letramento midiático. O cruzamento de variáveis associadas à percepção de letramento dos professores com a resposta deles se adotavam ou não práticas prévias de ensino de mídias aos alunos, indica associação moderada com correlação positiva.

Os resultados desses cruzamentos (conforme a Tabela 2), considerando as frequências esperadas e os resíduos ajustados, indicam que os professores que afirmaram ensinar mídia aos alunos se percebem como habilidosos em três das habilidades do questionário: "entender e explicar as linguagens utilizadas pelas mídias e a forma como elas são produzidas", "analisar e entender fotografias e imagens gráficas" e "compreender como e porque as mídias usam os dados de navegação na internet de seus usuários". Resultados similares foram encontrados na pesquisa realizada com professores espanhóis (COLÁsBRAVO; CONDE-JIMÉNEZ; GONZÁLEZ-RAMIREZ, 2016), mostrando que o uso de TIC na sala de aula e nas práticas pedagógicas consolida a percepção de segurança e o domínio das competências digitais dos professores.

Tabela 2. Resíduos ajustados padronizados de cruzamentos com significância no teste quiquadrado entre as variáveis: “O quanto você se considera capaz de...?” e sobre prática de letramento midiático antes da pandemia

\begin{tabular}{|c|c|c|c|c|c|c|}
\hline & Cruzamento & & $\begin{array}{l}\text { nto voc } \\
\text { agens } u\end{array}$ & $\begin{array}{r}\text { considera } \\
\text { das pelas } r \\
\text { prod }\end{array}$ & $\begin{array}{l}\text { az de enten } \\
\text { as e a form } \\
\text { das? }\end{array}$ & $\begin{array}{l}\text { e explicar as } \\
\text { omo elas são }\end{array}$ \\
\hline & 1 & Nada & $\begin{array}{l}\text { Muito } \\
\text { pouco }\end{array}$ & $\begin{array}{l}\text { Mais ou } \\
\text { menos }\end{array}$ & Bastante & Extremamente \\
\hline & Não & 0,9 & $3,3^{*}$ & $-0,1$ & $-1,6$ & $-1,4$ \\
\hline $\begin{array}{c}\text { Antes da interrupção das } \\
\text { aulas você costumava }\end{array}$ & Sim & $-0,9$ & $-3,3^{*}$ & 0,1 & 1,6 & 1,4 \\
\hline $\begin{array}{l}\text { propor práticas } \\
\text { pedagógicas de letramento } \\
\text { midiático para os seus }\end{array}$ & Cruzamento & O quar & você se & $\begin{array}{l}\text { idera capa } \\
\text { nagens grá }\end{array}$ & $\begin{array}{l}\text { analisar/e } \\
\text { s em geral? }\end{array}$ & nder fotografias e \\
\hline alunos na escola? & 2 & Nada & $\begin{array}{l}\text { Muito } \\
\text { pouco }\end{array}$ & $\begin{array}{l}\text { Mais ou } \\
\text { menos }\end{array}$ & Bastante & Extremamente \\
\hline & Não & 1,2 & $2,9^{*}$ & $2,5^{*}$ & $-3,2 *$ & $-0,9$ \\
\hline & Sim & $-1,2$ & $-2,9 *$ & $-2,5^{*}$ & $3,2^{*}$ & 0,9 \\
\hline & Cruzamento & $\begin{array}{l}\text { O quar } \\
\text { as } \mathrm{m}\end{array}$ & $\begin{array}{l}\text { você se } \\
\text { s digitai }\end{array}$ & $\begin{array}{l}\text { idera capa } \\
\text { im os dadc }\end{array}$ & $\begin{array}{l}\text { compreen } \\
\text { os seus usu }\end{array}$ & $\begin{array}{l}\text { como e para que } \\
\text { os quando estes }\end{array}$ \\
\hline (C) ETD-Educação Temo & ica Digital & Camp & IS, SP & n.1 & p. $32-52$ & jan./abr. 2022 \\
\hline
\end{tabular}


Uma explicação possível para a correlação entre ser professor de escola particular e a percepção de alta capacidade de produção de conteúdos em mídias é de que esse professor tenha recebido maior apoio por parte da gestão escolar e tenha tido mais formações específicas para atuar no ensino remoto, como indicam os resultados de pesquisa realizada pelo Instituto Península, em março de 2020. A pesquisa aponta que "professores que atuam na rede privada parecem estar mais preparados com a interação remota, se comparados aos docentes das redes estaduais e municipais" e que "as redes privadas de educação parecem estar conseguindo oferecer mais suporte à distância aos alunos, se comparado às redes estaduais e municipais." (INSTITUTO PENÍNSULA, 2020, p. 10).

Também se encontrou associação moderada entre dar aula na rede pública estadual e a capacidade de "compreender como e para que as mídias digitais usam os dados dos seus usuários quando estes navegam na internet" (Tabela 4). Essa associação se evidencia com mais impacto no fato de mais professores da rede pública estadual terem indicado que se consideram "nada capazes" nesse quesito (frequência observada: 6; frequência esperada: $2,6)$. Ou seja, os resultados sugerem maior probabilidade de professores da rede estadual se sentirem menos habilitados para compreender o uso que as plataformas digitais fazem dos dados de navegação de seus usuários. Esse achado torna-se mais significativo quando vemos que os recursos mais utilizados para apoiar as experiências de educação remota são sites $(66,8 \%)$, redes sociais $(63,3 \%)$ e plataformas de ensino a distância $(60,6 \%)$, a maioria proprietárias.

Tabela 4. Resíduos ajustados padronizados de cruzamento com significância entre as variáveis: "O quanto você se considera capaz de...?” e "Dá aula em escola pública estadual?"

\begin{tabular}{|c|c|c|c|c|c|c|}
\hline \multirow{4}{*}{$\begin{array}{l}\text { Dá aula em } \\
\text { escola pública } \\
\text { estadual? }\end{array}$} & \multirow{2}{*}{$\begin{array}{c}\text { Cruzamento } \\
1\end{array}$} & \multicolumn{5}{|c|}{$\begin{array}{l}\text { O quanto você se considera capaz de compreender como e para que as mídias } \\
\text { digitais usam os dados dos seus usuários quando estes navegam na internet? }\end{array}$} \\
\hline & & Nada & Muito pouco & Mais ou menos & Bastante & Extremamente \\
\hline & Não & $-2,6 *$ & $2,5^{*}$ & $-1,7$ & 1,3 & 0 \\
\hline & Sim & $2,6^{*}$ & $-2,5^{*}$ & 1,7 & $-1,3$ & 0 \\
\hline
\end{tabular}

Fonte: Os autores, pesquisa de campo.

Notas: $\mathrm{N}=259 ;{ }^{*}$ Resíduo ajustado padronizado significativo $(-1,96 ; 1,96)$

Cruzamento 1: Valor de p: 0,004 (significativo) | V de Cramer: 0,244 (associação moderada) 
Há alguns anos, pesquisadores brasileiros (EVANGELISTA, 2017; BONILLA; PRETTO, 2015) alertam para o aumento dos riscos associados à entrega de dados de órgãos públicos a plataformas privadas de gestão pública e de atividades educacionais, situação que se agravou durante a pandemia da Covid-19 (CRUZ; VENTURINE, 2020). O fato de professores de escolas estaduais não saberem o que as plataformas educacionais fazem com seus dados e com os materiais criados por eles indica que estão vulneráveis aos grandes grupos privados que gerenciam essas plataformas (Alphabet Inc., que controla o Google, e Microsoft, por exemplo) e que também estão pouco preparados para orientar seus alunos sobre o tema.

A grande quantidade de dados (big data) coletada de usuários e o uso de algoritmos para tratar esses dados através de inteligência artificial fazem parte do modelo de negócio das grandes empresas de tecnologia, as chamadas "big tech", que são a base do funcionamento do capitalismo digital e se apresentam como detentoras de soluções para diversos problemas da sociedade, desde o transporte público, os cuidados com a saúde, a educação, os meios de comunicação, entre outros (MOROZOV, 2018). A forma como o capitalismo digital opera leva também a problemas consideráveis, como a estandardização das práticas escolares, desconsiderando os diferentes contextos socioeconômicos e culturais e a diversidade dos alunos, a disseminação de notícias falsas e a vigilância e controle dos usuários.

Em relação ao uso de habilidade relacionadas aos letramentos midiáticos nas atividades de ensino remoto emergencial, o Gráfico 2 mostra uma alta porcentagem de professores que dizem estar utilizando todas as habilidades de letramento em suas práticas pedagógicas em ambiente digital, o que pode estar relacionado ao fato de estarem adotando atividades educacionais em formatos raramente implementados antes em contexto escolar (COMITÊ GESTOR DA INTERNET NO BRASIL, 2020). Esses professores certamente estão experimentando e aprendendo novas habilidades relacionadas ao uso pedagógico das mídias e isso pode vir a ser um legado importante do ensino remoto emergencial, como argumentam Viana et al (2020), em relato de pesquisa sobre a experiência e as aprendizagens de professores nesse contexto de ensino. 
Gráfico 2. Quanto essas habilidades estão sendo utilizadas por você nesse momento de educação remota? (porcentagem)

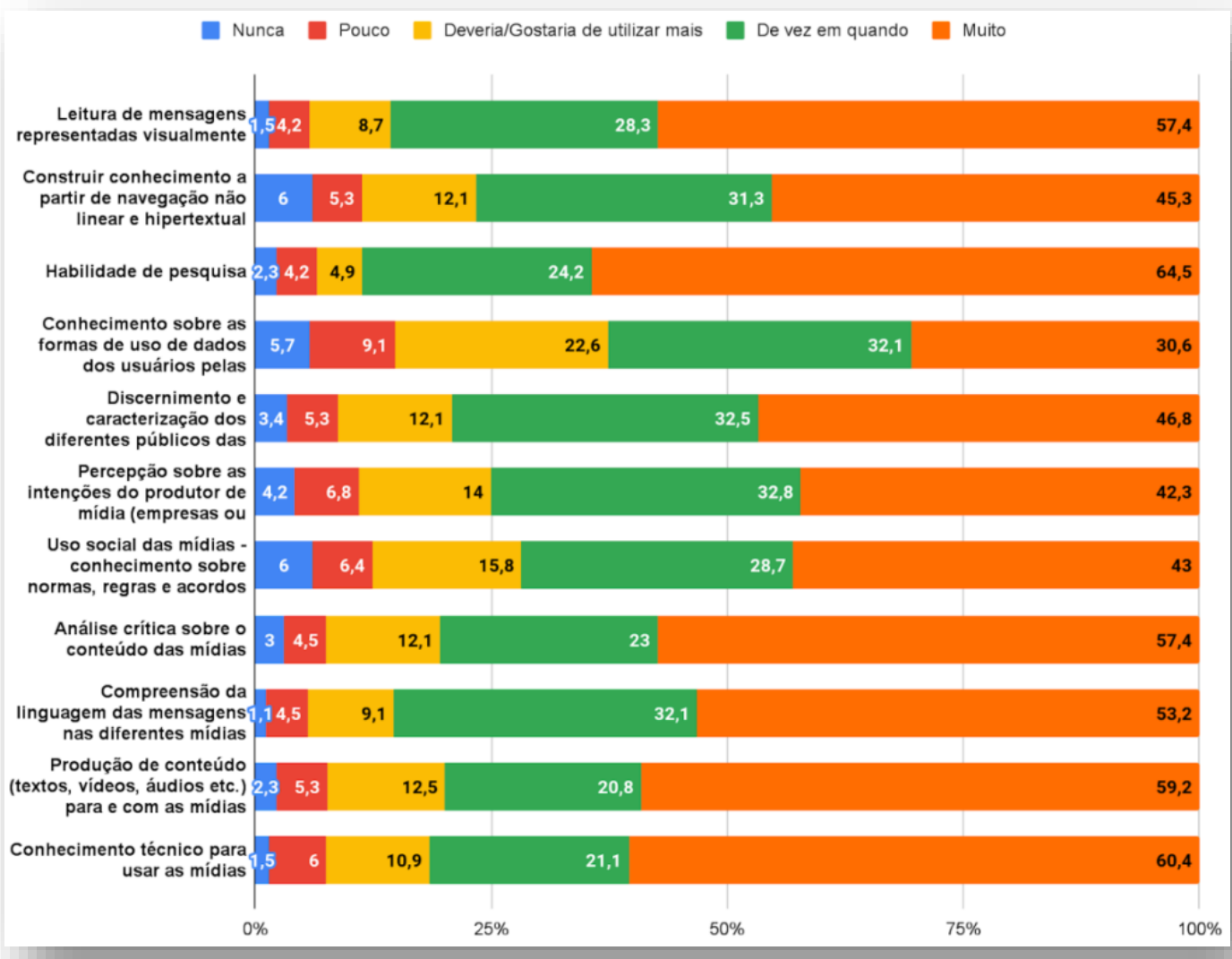

Fonte: Os autores, pesquisa de campo.

O cruzamento das respostas à pergunta sobre se os professores empregam suas habilidades de letramento midiático na educação remota com as respostas sobre o costume de realizar práticas de letramento midiático em sala de aula antes da pandemia indicou correlação positiva entre as duas variáveis. Ou seja, ter realizado atividades de letramento com os alunos antes influenciou a probabilidade de o professor fazer uso de suas habilidades de letramento nas atividades de educação remota, como se pode perceber na tabela a seguir. 
Tabela 5. Resíduos ajustados padronizados de cruzamentos com significância no teste quiquadrado entre as variáveis "Quanto essas habilidades estão sendo utilizadas por você...?" e variável sobre prática de letramento midiático antes da pandemia

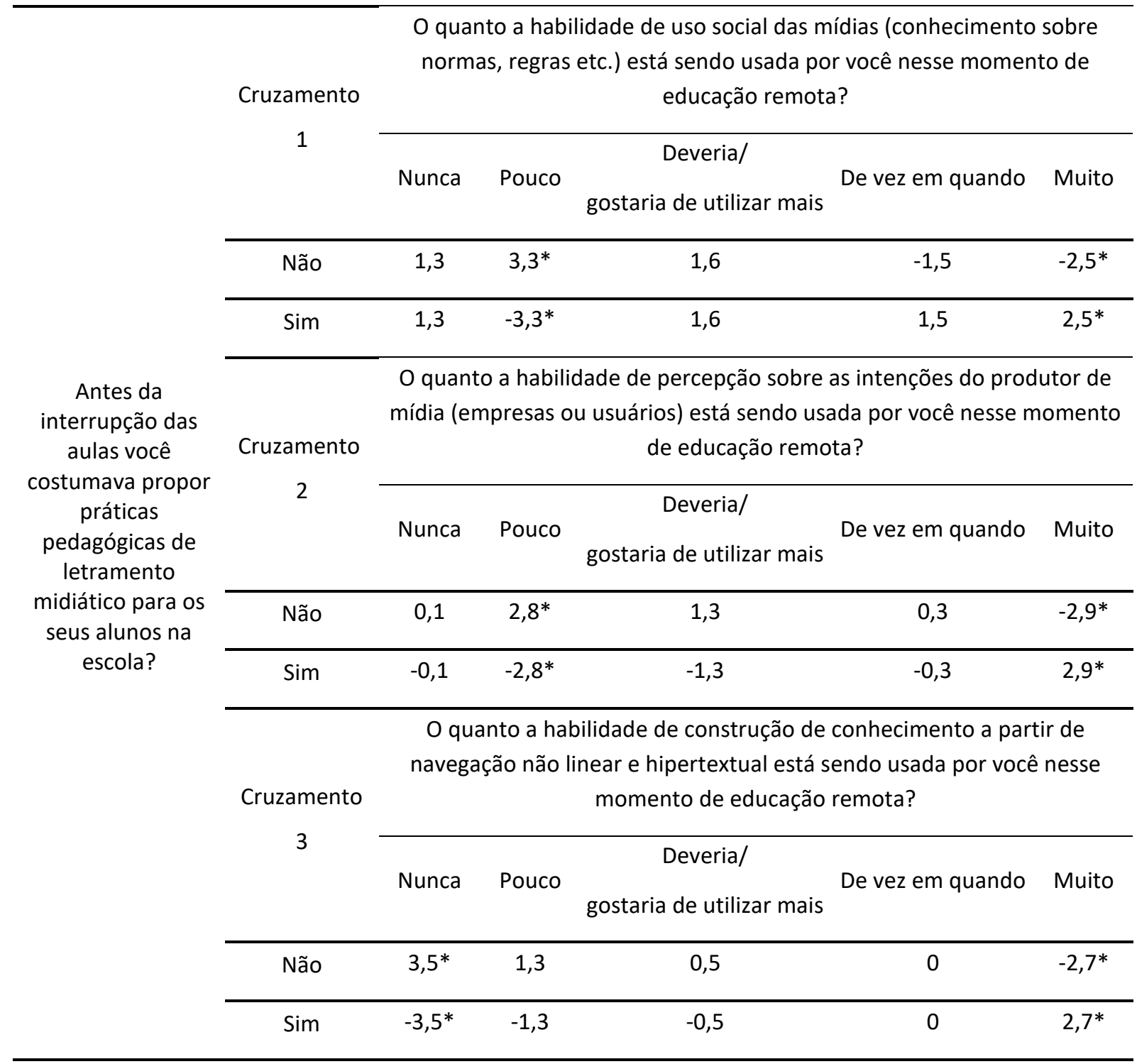

Fonte: Os autores, pesquisa de campo.

Notas: $\mathrm{N}=256$ | Casos omissos: quem respondeu "não sei" à questão da prática de letramento midiático

*Resíduo ajustado padronizado significativo $(-1,96 ; 1,96)$

Cruzamento 1: Valor de p: 0,001 (significativo) | V de Cramer: 0,265 (associação moderada)

Cruzamento 2: Valor de p: 0,01 (significativo) | V de Cramer: 0,227 (associação moderada)

Cruzamento 3: Valor de p: 0,002 (significativo) | V de Cramer: 0,259 (associação moderada)

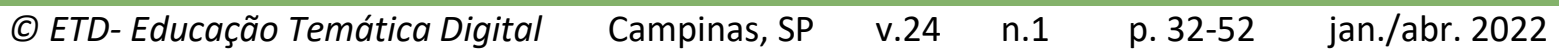




\section{CONSIDERAÇÕES FINAIS}

Em estudo recente, a Fundação Abrinq (2021) analisou e consolidou dados de natureza socioeconômica relacionados à educação, extraídos da Pnad Contínua, realizada pelo IBGE, em parceria com o Ministério da Saúde para monitorar a incidência da Covid-19 em todo o território nacional. Os resultados evidenciam as enormes desigualdades de acesso ao ensino remoto e o quanto estas refletem diretamente as desigualdades socioeconômicas presentes no país. Esta realidade tem sido comprovada em diversos estudos e reflexões recentemente publicados (ALEVIZOU, 2020; FACER; SELWYN, 2021; SAHLBERG, 2021; UNICEF, 2021), que mostram o quanto a eficácia do ensino remoto emergencial depende de fatores que já impactavam a educação escolar - demográficos, socioeconômicos, de infraestrutura tecnológica, formação dos professores, entre outros - e que nenhuma estratégia educacional na pandemia será bem-sucedida sem que sejam adotadas medidas para redução dos efeitos desses fatores.

A pesquisa aqui relatada tinha como pressuposto que um maior letramento midiático de professores poderia ser um elemento favorável à obtenção de melhores resultados na implementação do ensino remoto emergencial, uma vez que as habilidades de uso pedagógico de mídias são imprescindíveis para a qualidade das atividades educativas em ambiente digital. Os resultados apontam para uma percepção elevada de habilidades de letramento midiático, por parte dos professores que estão realizando ensino remoto emergencial, e o uso de muitas dessas habilidades nas suas práticas pedagógicas on-line. Indicam, também, que a realização de práticas de letramento midiático pelos professores junto aos alunos na escola, antes da pandemia, favoreceu a percepção de alta competência para o uso de mídias na educação digital remota. Isso reforça argumentos de outros pesquisadores (BONILLA; PRETTO, 2015; HEINSFELD; PISCHETOLA, 2019) de que a inserção de TIC na escola que prioriza o desenvolvimento de habilidades, em detrimento do uso instrumental, contribuindo para a adoção crítica dessas tecnologias nas práticas pedagógicas.

Se por um lado a experiência do ensino remoto emergencial resultou em aprendizados que dotaram professores de competências que eles certamente não tinham antes, por outro, os deixou expostos ao uso indiscriminado de seus dados de navegação e de suas estratégias didáticas pelas plataformas proprietárias educacionais. Segundo Morozov (2018), na era do capitalismo "dadocêntrico", as chamadas big techs, convertem todos os aspectos da nossa existência (trabalho, escola, lazer etc.) em ativos rentáveis através do uso de nossos dados. O autor chama a atenção também para o fato da nossa privacidade estar se tornando mercadoria, já que hoje é necessária grande expertise, que 
tem um alto custo, para poder navegar na rede com liberdade e poder, de fato, desfrutar de privacidade.

No ensino remoto, muitos professores e estudantes se viram obrigados a utilizar as plataformas privadas de ensino, como Google Classroom e Microsoft Teams, além de redes sociais, como Facebook e WhatsApp, alimentando-as com um volume gigantesco de informações pessoais. Face a isso, uma das habilidades de letramento midiático fundamental no momento é exatamente aquela relacionada à compreensão da estrutura desse capitalismo dadocêntrico e das razões pelas quais as mídias se apropriam dos dados de seus usuários. Os resultados aqui apresentados indicam que essa ainda é uma habilidade muito incipiente entre os professores de escolas públicas estaduais, e um pouco mais desenvolvida entre professores de escolas privadas.

Considerando esse contexto, reafirmamos o argumento de outros pesquisadores (BUKINGHAM, 2020; LIVINGSTONE, 2011) em torno da necessidade de uma abordagem crítica para o letramento midiático, com foco no conhecimento das plataformas digitais e do controle dos nossos dados pela inteligência artificial, que está na base do seu funcionamento - saber indispensável para compreender o tipo e a qualidade das informações obtidas na internet. Entender como opera o chamado capitalismo digital (MOROZOV, 2018) tornou-se condição para as práticas sociais e educativas de uso das mídias, especialmente no momento em que nos tornamos dependentes das tecnologias para ensino, estudo, trabalho e participação na vida social.

\section{REFERÊNCIAS}

ALEVIZOU, Giota. Virtual schooling, covid-inequalities: building resilience and digital literacies for uncertain futures. Digital Culture \& Education, 2020.

ATA, RIdvan; YILDIRIM, Kasım. Exploring Turkish pre-service teachers' perceptions and views of digital literacy. Education Sciences, v. 9, n. 40, 2019.

BONILLA, Maria Helena Silveira; PRETTO, Nelson De Luca. Movimentos colaborativos, tecnologias digitais e educação. Em Aberto, Brasília, v. 28, n. 94, p. 23-40, jul./dez. 2015.

BRASIL. Censo da Educação Básica 2019: resumo técnico. Brasília: INEP, 2020. Disponível em: https://tinyurl.com/2spwv7hy Acesso em: 2 jul. 2021.

BRASIL. Ministério da Saúde. Comissão Nacional de Ética em Pesquisa (CONEP). Orientações para procedimentos em pesquisa com qualquer etapa em ambiente virtual. Brasília, DF, mar. de 2021. Disponível em: https://tinyurl.com/4j8vppem Acesso em: 2 jul. 2021. 
BRASILINO, Aline de Mendonça. Formação de Professores e a prática pedagógica com tecnologias: estudo da correlação na base TIC Educação 2014. 2017. Dissertação (Mestrado em Educação) - Pontifícia Universidade Católica do Rio de Janeiro, Rio de Janeiro: 2017.

BUCKINGHAM, David. The media education manifesto. Cambridge: Polity Press, 2019.

BUCKINGHAM, David. Epilogue: Rethinking digital literacy: media education in the age of digital capitalism. Digital Education Review, n. 37, p. 230-239, 2020.

BUZATO, Marcelo El Khouri. Cultura digital e apropriação ascendente: apontamentos para uma educação 2.0. Educação em Revista, v. 26, n. 3, p. 283-303, 2010.

COLÁS-BRAVO, Pilar; CONDE-JIMÉNEZ, Jesús; GONZÁLEZ-RAMÍREZ, Teresa. Spanish teachers' perception of their own and their students' digital competencies. In: CRISAN, Marius-Mircea; TOMA, Roxana-Andrea. Beliefs and behaviours in education and culture: cultural determinants and education. Bucureşti, Rumanía: Pro Universitaria, 2016. p. 42-53.

COMITÊ GESTOR DA INTERNET NO BRASIL (CGI.br). Pesquisa sobre o uso das tecnologias de informação e comunicação nas escolas brasileiras: TIC Educação 2019. São Paulo, 2020.

CRUZ, Leonardo Ribeiro Da; VENTURINI, Jamila Rodrigues. Neoliberalismo e crise: o avanço silencioso do capitalismo de vigilância na educação brasileira durante a pandemia da Covid19. Revista Brasileira de Informática na Educ., v. 28, p. 1060-1085, dez. 2020.

CRUZ, Priscila; MONTEIRO, Luciano. Anuário Brasileiro da Educação Básica 2020. São Paulo: [s.:n.]. Disponível em: https://tinyurl.com/3yj96tu3 Acesso em: 2 jul. 2021.

ESHET-ALKALAI, Yoram. Thinking in the digital era: a revised model for digital literacy. Issues in Informing Science \& Information Technology, v. 9, p. 267-276, 2012.

EVANGELISTA, Rafael De Almeida. Capitalismo de vigilância no sul global: Por uma perspectiva situada. In: SIMPÓSIO INTERNACIONAL LAVITS, 5., 2017, Santiago-Chile. Anais [...]. Santiago, 2017. p. 243-253.

FACER, Keri; SELWYN, Neil. Digital technology and the futures of education: towards "nonstupid" optimism. UNESCO - Futures of Education Report. 2021.

FIELD, Andy. Discovering Statistics Using IBM SPSS Statistics. 3rd. ed. SAGE, 2009.

FUNDAÇÃO ABRINQ. Cenário da infância e adolescência no Brasil 2021. São Paulo, 2021. Disponível em: https://tinyurl.com/ykxmhefb Acesso em: 2 jul. 2021.

FUNDO DAS NAÇÕES UNIDAS PARA A INFÂNCIA (UNICEF). Cenário da exclusão escolar no Brasil: um alerta sobre os impactos da pandemia da COVID-19 na educação. [s.:I.: s.:n.]. Disponível em: https://tinyurl.com/aryna882 Acesso em: 3 dez. 2021. 
HANDCOCK, Mark S.; GILE, Krista J. On the concept of snowball sampling. Sociological Methodology, v. 41, n. 1, p. 367-371, 2011.

HEINSFELD, Bruna Damiana; PISCHETOLA, Magda. O discurso sobre tecnologias nas políticas públicas em educação. Educação \& Pesquisa, v. 45, 2019.

HODGES, CHARLES; MOORE, STEPHANIE; LOCKEE, BARB; TRUST, TORREY; BOND, Aaron. The difference between emergency remote teaching and online learning. Educause Review, mar. 2020.

INSTITUTO PENÍNSULA. Sentimento e percepção dos professores brasileiros nos diferentes estágios do coronavírus no Brasil. São Paulo, mar. 2020. Disponível em:

https://tinyurl.com/3fm4rb76 Acesso em: 2 maio 2021.

JENKINS, Henry. Cultura da convergência. São Paulo: Aleph, 2009.

LIMA, Ana Lúcia D' Império. Retratos da Educação no contexto da pandemia do coronavírus: um olhar sobre múltiplas desigualdades. São Paulo: Rede Conhecimento Social, 2020. Disponível em: https://tinyurl.com/3umfvkwj Acesso em: 2 maio 2021.

LIVINGSTONE, S. Internet literacy: a negociação dos jovens com as novas oportunidades online. Matrizes, n. 2, p. 11-42, 2011.

LUCAS, Margarida; MOREIRA, António. DigCompEdu: quadro europeu de competência digital para educadores. Aveiro: UA, 2018.

LUPTON, Deborah. 12 Perspectives on the pandemic. In: BOOMGAARDEN, Gerhard (ed.). 12 perspectives on the pandemic. Berlin: Walter de Gruyter GmbH, p. 50-56, 2020.

MOROZOV, Evgeny. Big tech: a ascensão dos dados e a morte da política. São Paulo: Ubu Editora, 2018.

ORGANIZAÇÃO DAS NAÇÕES UNIDAS PARA A EDUCAÇÃO, A CIÊNCIA E A CULTURA

(UNESCO). Education: from disruption to recovery. Disponível em:

https://en.unesco.org/covid19/educationresponse Acesso em: 3 dez. 2020.

PEREIRA, Sara. Educação para os media hoje: alguns princípios fundamentais. Cadernos do Noroeste: Série de Comunicação, v. 14, p. 1-2, p. 669-674, 2000.

PEREIRA, Sara; PINTO, Manuel; MOURA, Pedro. Níveis de literacia mediática: estudo exploratório com jovens do $12^{\circ}$ ano. Braga: CECS - Portugal, 2015.

REA, Louis M.; PARKER, Richard. A. Designing and conducting survey research. 4. ed. San Francisco, CA: Jossey-Bass, 2014. 
SAHLBERG, Pasi. Does the pandemic help us make education more equitable?. Educ Res Policy Prac., v. 20, p. 11-18, 2021. Disponível em: https://doi.org/10.1007/s10671-02009284-4 Acesso em: 15 nov. 2021.

SANTOS, Boaventura de Souza. A cruel pedagogia do vírus. São Paulo: Edições Almedina, 2020.

SCOLARI, Carlos A. Adolescentes, medios de comunicación y culturas colaborativas: aprovechando las competencias transmedia de los jóvenes en el aula. Barcelona, 2018.

SHARPE, Donald. Chi-square test is statistically significant: now what? Practical Assessment, Research and Evaluation, v. 20, n. 8, abr. 2015.

SOARES, Magda. Novas práticas de leitura e escrita: letramento na cibercultura. Educação \& Sociedade, v. 23, n. 81, p. 143-160, 2002.

VIANA, Thereza Cristina Bertrazzo S.; ENGERROFF, Ana Carina Baron; LAPA, Andrea; LOUREIRO, Carla Cristiane; SOLIGO, Marina Guazelli. Atividades pedagógicas não presenciais: desafios da experiência docente do CA/UFSC durante a pandemia. Sobre Tudo, v. 11, p. 29-54, 2020.

Revisão gramatical realizada por Mirna Juliana Santos Fonseca

E-mail: mirnarevisora@gmail.com 